\title{
Survival in extremes
}

\author{
Piotr H. Malecki, Wojciech RyPniewski * \\ Institute of Bioorganic Chemistry, Polish Academy of Sciences, Poznań, Poland \\ * Corresponding author: wojtekr@ibch.poznan.pl
}

\begin{abstract}
Demand is growing for extremozymes for biotechnological purposes. Extremophilic organisms are a natural source of enzymes that possess features desired by the biotechnology and medical industries. X-ray crystallography can reveal the nature of enzyme adaptation strategies to extreme environments.
\end{abstract}

\section{Biotechnological aspects of temperature adaptation}

Ever since our ancestors made their first simple tools, mankind has continually been looking for new materials from the natural environment to overcome life's obstacles and to thrive. Today, our knowledge about the world around us has extended to the molecular scale as a result of the advent of the age of molecular biology. This has enabled us to gain insight into molecular mechanisms and even to describe the spacial arrangement of atoms in bio-molecules, which promises applications in the agricultural, energy, medical and food industries. As concerns for the environment grow, environmentally detrimental chemical and physical processes can be effectively replaced by biological tools, such as enzymes. The use of natural enzymes in industry has increased not only as an effect of environmental concerns but also because they turn out to be effective and cost-efficient alternatives to traditional industrial processes (Brenchley, 1996; Ohgiya et al., 1999; Gerday et al., 2000; Allen et al., 2001; Cavicchioli et al., 2002). Enzymes have been used since ancient times, because these natural biocatalysts are endowed with a high catalytic power, substrate specificity and ability to work in mild conditions. The unique properties of enzymes (extreme stability or very high catalytic power) make them useful in biotechnology, and extremophilic organisms are a natural source of such enzymes. Extremophiles are organisms requiring extreme environments for growth, and the enzymes they produce are called extremozymes (Hough et al., 1999). Life in a harsh environment has enabled adaptation of their enzymatic machinery, allowing them to survive and even multiply in conditions where life is hard to imagine, from our egocentric point of view. Nowadays, the time has come to explore extreme environments, such as cold deep seas or hot spots (eg. deep sea hydrothermal vents, volcanoes), to find hosts for potentially attractive extremozymes.

\section{Deep inside the cold biosphere}

Cold environments are the most abundant on Earth and temperatures permanently below $5{ }^{\circ} \mathrm{C}$ extend over an estimated $75 \%$ of the biosphere, including the deepsea, the polar and alpine regions, and subterranean caves. This area is successfully colonised by organisms known as psychrophiles (optimal growth $<15^{\circ} \mathrm{C}$ ), including bacteria (Deming, 2002), Archaea (Cavicchioli, 2006), Eukarya (Peck, 2002) and also viruses (Wells and Deming, 2006). These organisms are adapted to live, grow and multiply there. It is worth mentioning that psychrophilic organisms can catalyze reactions at $4{ }^{\circ} \mathrm{C}$ at rates comparable to their mezophilic counterparts at $37^{\circ} \mathrm{C}$ (Pomeroy and Wiebe, 2001). In addition, they possess a doubling time comparable to $E$. coli (Feller and Gerday, 2003). This makes them very interesting for biotechnological applications. In addition to many general strategies developed for survival and the maintainace of living processes in the cold (eg. alterations in membrane fluidity (Russell, 1997), expression of anti-freezing proteins (Muryoi et al., 2004), production of compatible solutes and exopolysaccharides (Nichols et al., 2005)) enzymes from cold-adapted organisms must be able to maintain activity not only in low temperatures but also in other extremes, such as high salt concentrations (ha- 
lophiles) or high pressure in the sea (piezophiles). Psychrophilic enzymes display high catalytic efficiency and are most often, if not always, associated with thermosensitivity. It seems that there are many adaptation paths for psychrophilic enzymes and that is why it has been the aim of many scientists to elucidate the exact features responsible for their unusual properties. In addition to specific amino acid composition, the high catalytic activity of psychrophilic enzymes is explained by an increased flexibility of the molecules (D'Amico et al., 2002; Gianese et al., 2002).

\section{Surviving in the hot}

In contrast to cold-adapted microorganisms, thermophiles need to have a hot environment to thrive and are found in hot springs, deep see thermal vents or decayed wood. They can be generally classified, depending on the optimum growth temperature, into 3 groups: moderate thermophiles $\left(50-60^{\circ} \mathrm{C}\right)$, extreme thermophiles $\left(60-80^{\circ} \mathrm{C}\right)$ and hyperthermophiles $\left(80-110^{\circ} \mathrm{C}\right)$. Thermophilic microorganisms have attracted the most attention and are studied because of their temperature resistant enzymatic machinery. The main advantage of thermophilic enzymes is their conformational stability in high or very high temperatures (Pyrpassopoylos, 2006). Most normal enzymes, being proteins, denature and lose activity above $40^{\circ} \mathrm{C}$. Extremozymes derived from thermophiles are much better suited for harsh industrial processes. Despite the high energy consumption, biotechnological processes conducted in high temperatures have many advantages, such as the increased solubility of substrates, increased availability of substrates, higher catalytic rate and decreased risk of bio-contamination.

\section{Best model for comparative studies}

Enzymes are suitable models for addressing questions about temperature adaptation. They need to be stable in order to maintain the 3-D structure required for activity but also flexible to allow conformation changes during catalysis. These two requirements affect extremozymes even more, because they must be both stable and active in harsh conditions.

These properties can be investigated using X-ray crystallography but the rules governing their adaptation appear to be diverse. It seems that the fold $\beta / \alpha$-barrel, also called a TIM barrel, is an excellent model system

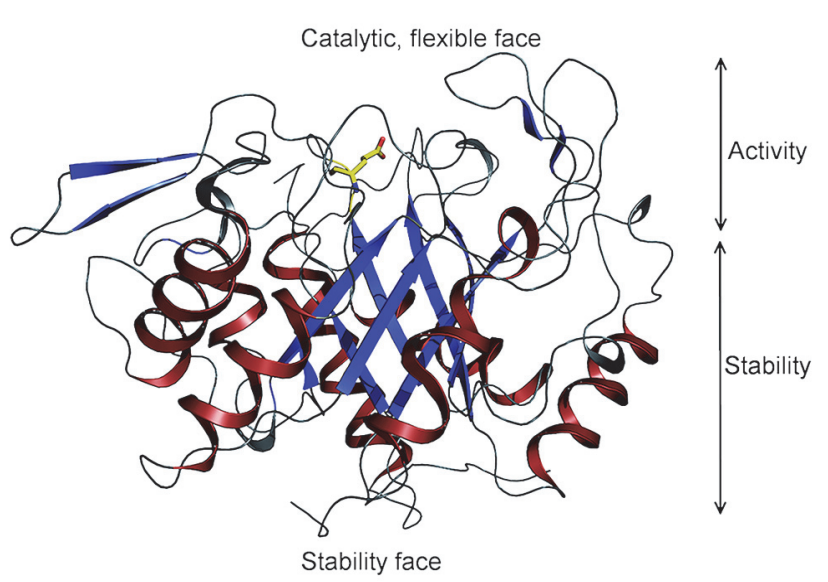

Fig. 1. Division of $\beta / \alpha$-barrels based on the catalytic domain of chitinase 60 . Active residue is shown in stick representation

for comparative studies. About $10 \%$ of all proteins with known structure have a $\beta / \alpha$-barrel module (Gerlt, 2001; Wierenga, 2001). These are versatile enzymes, having the activity of oxidoreductases, transferases, lyases, hydrolases and isomerases (Pujadas, 1999). The fold of the canonical $\beta / \alpha$-barrel domain consists of an internal barrel made of an eight-stranded parallel $\beta$ sheet surrounded by eight $\alpha$ helices. The active site is located at the carboxyl ends of the strands and also comprises loops linking $\beta$-strands with subsequent $\alpha$ helices. This part is believed to be essential for activity and thus must be flexible to adapt to the cold. In contrast, the opposite face of the barrel is important for stabilizing the fold (Fig. 1). This dual character of the structure makes it possible to change the catalytic activity without debilitating the stability (Höcker et al., 2001).

\section{Psychrophilic chitinase \\ from the marine bacterium (Moritella marina)}

For extremophilic microorganisms living on the bottom of the sea, "marine snow" (organic detritus falling from the upper layers of the sea) is one of the most important sources of carbon. It contains chitin, a very abundant insoluble bio-polymer in the marine environment, composed of a linear polymer of $\beta$-1,4-linked N-acetyl-Dglucosamine residues, with the chains closely connected by hydrogen bonds. After cellulose, chitin is the second most abundant bio-polymer in nature.

Chitinases produced by marine bacteria, such as $\mathrm{Mo}$ ritella marina, should have high catalytic activity under these low-temperature conditions, not to mention high pressure (Stefanidi, 2008). In the past few years, several 


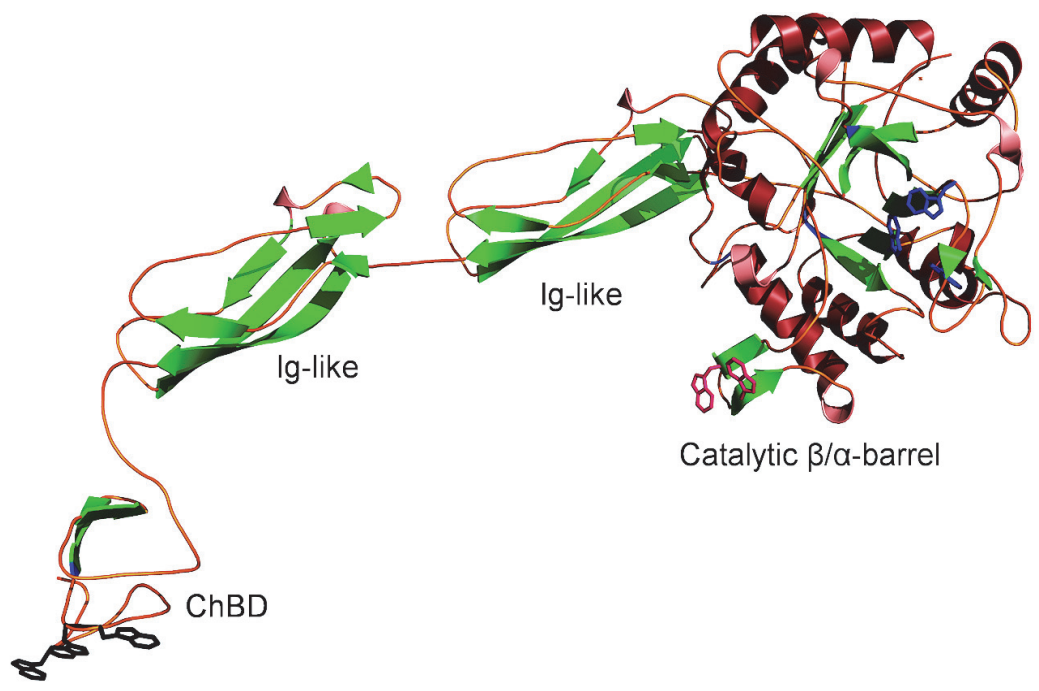

Fig. 2. Cartoon plot of MmChi60 with four domains labelled. Tryptophan residues believed to be significant in chitin binding are shown: in the chitin-binding domain, black; in the catalytic domain, pink; lining the active site, blue

psychrophilic chitinases have been reported but only our group has solved a complete structure using X-ray crystallography. The crystal structures of an unliganded protein and a protein with several ligands revealed features that could play a role in adaptation to the cold. Flexibility, previously proposed as the most important factor for catalysis by psychrophiles, is observed here in many aspects. Overall, the structure is modular, elongated and consists of 4 domains: an $\mathrm{N}$-terminal catalytic $\beta / \alpha$-barrel (classed as glycoside hydrolase family 18; GH18), two bacterial immunoglobulin-like (Ig-like) domains known as the Big 3 domains (Pfam database ID PF07523); and a C-terminal chitin binding domain. Hinge regions have been detected between the Ig-like domains as well as between the second Ig-like domain and the adjacent ChBD. This kind of flexibility makes the enzyme more efficient in terms of accessing the substrate (the active site and the chitin binding domain are separated by $100 \AA$ ). Furthermore, the protein's affinity to the binding groove and ChBD is supplemented by additional chitin binding elements on the $\beta / \alpha$-barrel (Fig. 2) (Malecki et al., 2013).

Compared to most chitinases from mezophilic microorganisms, the active site and the substrate binding groove are also more flexible. They are both open to accommodate the substrate and the residues around the active site are flexible, significantly changing conformation during the catalysis.

\section{Conclusions}

Interdisciplinary studies of enzymes from extremophiles can enlighten discussion of possible methods of adaptation to conditions that are deadly for "normal" mezophilic enzymes. Crystallographic studies have shed light on extremozyme adaptation to harsh conditions. They have explained which particular features are important for adaptation to such an environment. This knowledge on structural properties and their effect on kinetics is essential in enhancing enzymes already used in the biotechnology industry. Extremophiles with their extraordinary enzymatic machinery are a source of extremozymes that could be used in industrial catalytic processes to decrease power consumption and make such processes more environmentally friendly.

\section{Acknowledgements}

Financial support for the project was provided by the European Union within the framework of the European Regional Developmental Fund.

\section{References}

Allen D., Huston A.L., Wells L.E., Deming J.W. (2001) In: Bitton G. (ed.) Wiley, New York, pp. 1-17.

Brenchley J.E., Loveland-Curtze J., Gutshall K., Humphrey V. (2001) Patent No. US6326346.

Cavicchioli R., Siddiqui K.S., Andrews D., Sowers K.R. (2002) Curr. Opin. Biotechnol. 13: 161-253. 
Cavicchioli R (2006) Nat. Rev. Microbiol. 4: 331-343.

D’Amico S., Claverie P., Collins T., Georlette D., Gratia E., Hoyoux A., Meuwis M.A., Feller G., Gerday C. (2002) Proc. R. Soc. B 257: 917-925.

Deming J.W. (2002) Curr. Opin. Microbiol. 3: 301-309.

Feller G., Gerday C. (2003) Nat. Rev. Microbiol. 1: 200-208.

Garsoux G., Georlette D., Hoyoux A., Lonhienne T., Meuwis M.A., Feller G. (2000) TIBTECH 18: 103-107.

Gerday C., Aittaleb M., Benhatir M., Chessa J.P., Claverie P., Collins T., D’Amico S., Dumont, J., Gerlt J.A., Babbitt P.C. (2001) Nat. Struct. Biol. 8: 5-7.

Gianese G., Bossa F., Pascarella S. (2002) Proteins 47: 236249.

Hough D.W., Danson M.J. (1999) Curr. Opin. Chem. Biol. 1: 39-46.

Höcker B., Jürgens C., Wilmanns M., Sterner R. (2001) Curr. Opin. Biotechnol. 12: 376-381.

Malecki P.H., Raczynska J.E., Vorgias C.E., Rypniewski W. (2013) Acta Crystallogr., Sect. D: Biol. Crystallogr. Accepted 21 January 2013.

Muryoi N., Sato M., Kaneko S., Kawahara H., Obata H., Yaish M.W., Griffith M., Glick B.R. (2004) J. Bacteriol. 186: 5661-5671.
Nichols C.M., Lardiere S.G., Bowman J.P., Nichols P.D., Gibson J.A.E., Guezennec J. (2005) Microb. Ecol. 49: 578589.

Ohgiya S., Hoshino T., Okuyama H., Tanaka S., Ishizaki K. (1999) In: Margesin R., Schinner F. (eds.) Springer, Berlin, pp. 17-34.

Peck L.S. (2002) Polar. Biol. 25: 31-40.

Pomeroy L.R., Wiebe W.J. (2001) Aquat. Microb. Ecol. 23: 187-204.

Pujadas G., Palau J. (1999) Biol. Bratisl. 54: 231-254.

Pyrpassopoylos S., Vlassi M., Tsortos A., Papanikolaou Y.K., Petratos K., Vorgias C.E., Nounesis G. (2006) Prot. Struct. Funct. Bioinf. 64: 513-523.

Russell N.J. (1997) Comp. Biochem. Physiol. Physiol. 118: 489-493.

Stefanidi E., Vorgias C.E. (2008) Extremophiles 12: 541-552.

Wells L.E., Deming J.W. (2006) Aquat. Microb. Ecol. 45: 1529.

Wierenga R.K. (2001) FEBS Lett. 492: 193-198. 